\title{
Queixas musculoesqueléticas e a prática de ginástica laboral de colaboradores de instituição financeira
}

\author{
José Eduardo Silveira Machado Júnior ${ }^{a *}$, Frederico Chaves Seger ${ }^{\mathrm{b}}$, Clarissa Stefani Teixeirac, \\ Érico Felden Pereira ${ }^{d}$, Eugenio Andrés Díaz Merino ${ }^{\mathrm{e}}$ \\ a*edumachadojr@gmail.com, UNIFRA, Brasil \\ bfred_zn@hotmail.com, Faculdade Don Bosco, Brasil \\ cclastefani@gmail.com, SOCIESC|UNICA, Brasil \\ dericofelden@gmail.com, UDESC, Brasil \\ emerino@deps.ufsc.br, UFSC, Brasil
}

\section{Resumo}

Este estudo identificou as queixas musculoesqueléticas de 16 trabalhadores de uma instituição financeira, praticantes e não praticantes de ginástica laboral, por meio do questionário do mapa corporal. Para a análise dos dados foi utilizado o teste qui-quadrado com nível de significância de 5\%. 0 grupo da ginástica laboral mostrou resultados positivos apenas para a análise da região cervical $(p=0,049)$, sendo as queixas nesta região mais leves $(44,44 \% ; n=4)$ quando comparadas às apresentadas pelos indivíduos não praticantes de ginástica laboral. Esses trabalhadores, por sua vez, apresentaram queixas mais intensas como as moderadas (intensidade 3) $(42,86 \% ; n=3)$ e consideráveis (intensidade 4) $(57,14 \% ; n=4)$. As práticas em ginástica laboral, realizadas duas vezes na semana, não foram suficientes para diferenciar a intensidade das queixas musculoesqueléticas na maioria das regiões corporais analisadas, indicando a necessidades de adequação das atividades realizadas visando maior efetividade em termos musculoesqueléticos.

Palavras-chave

Queixas musculoesqueléticas. Ginástica laboral. Ergonomia.

\section{Introdução}

0 trabalho enquanto atividade humana vem apresentando variações em seu conceito e em seus sentidos ao longo da história. 0 mundo do trabalho ultrapassou os procedimentos rudimentares, chegando à automação, forma em torno da qual o trabalho está organizado na contemporaneidade. A atividade financeira também seguiu esse caminho, transpondo condições de intenso trabalho manual, como, por exemplo, fazer manualmente toda a contabilidade, para as mais modernas tecnologias (GRAVINA; ROCHA, 2006), o que tem causado impacto no desenvolvimento da atividade laboral (BRANDÃO; HORTA; TOMASI, 2005).

No Brasil, de acordo com Ely (1996), existiram 3 fases importantes no setor financeiro: a primeira fase foi a criação dos Centros de Processamento de Dados em 1964 e do Banco Central do Brasil em 1967, cujo objetivo era controlar a situação financeira do país. A segunda fase teve seu início na década de 70 com a introdução do sistema on-line. A terceira fase, ocorrida no final dos anos 80 , constituiu-se na intensificação da automação bancária. Nesta fase foram introduzidas no serviço bancário ações inovadoras tais como: criação de agências virtuais e caixas eletrônicos, cartões magnéticos, atendimento a clientes em casa ou no trabalho, compensação eletrônica, leitura óptica de cheques e a interligação entre bancos e empresas.

Segundo Murofuse e Marziale (2001), a introdução da automação em larga escala com a crescente utilização dos microcomputadores em todos os setores produtivos tem ocasionado rotinas de trabalho altamente rápidas e repetitivas e, no caso dos trabalhadores do sistema financeiro, essas considerações não são diferentes. 0 que ocorre é que as mudanças têm provocado novas exigências físicas 
e mentais, modificando o padrão de desgaste dos trabalhadores e suas condições de saúde.

Nesse sentido, as queixas musculoesqueléticas são sintomas que preocupam não apenas quando se associam a eficácia e eficiência do trabalho, mas também quando se associam os afastamentos dele em função dessas queixas. Segundo Gravina e Rocha (2006), os adoecimentos da profissão estão relacionados tanto à automação quanto à mudança no perfil do trabalho.

A busca por estratégias que visam a diminuição ou atenuação desses sintomas indica a prática de exercícios físicos, que dentro das empresas caracterizam-se como sendo a prática de ginástica laboral (BRANDÃO; HORTA; TOMASI, 2005). Essas práticas visam prevenir e diminuir a incidência de lesões por esforço repetitivo ou distúrbios osteomusculares relacionados ao trabalho (OLIVEIRA, 2006) e proporcionar benefícios físicos, fisiológicos, psicológicos e sociais do trabalhador, influenciando a qualidade de vida e gerando melhorias no ambiente de trabalho e na produtividade (ZILLl, 2002).

Além disso, Ceschini, Romero e Lima (2007) indicam que, em trabalhadores, muito tem se falado e divulgado sobre os benefícios da prática regular de atividade física para a saúde e a importância de programas de qualidade de vida dentro das empresas. Assim, este estudo buscou identificar as queixas musculoesqueléticas em colaboradores de uma instituição financeira privada, praticantes e não praticantes de ginástica laboral.

\section{Metodologia}

Foram avaliados os colaboradores de uma instituição financeira privada da região Sul do Brasil. No total, participaram do estudo 16 funcionários, com idade média de 26,69 \pm 6,77 anos, sendo $6(37,5 \%)$ do gênero feminino e $10(62,5 \%)$ do gênero masculino. Os indivíduos foram divididos em dois grupos: praticantes e não praticantes de atividades de ginástica laboral proporcionada pela empresa. Assim, 7 (43,75\%) indivíduos afirmaram participar das atividades e $9(56,25 \%)$ não realizavam as práticas propostas.

As queixas musculoesqueléticas foram verificadas por meio do questionário do mapa corporal (KUORINKA et al., 1987; ENGQUIST; ØRBAEK; JAKOBSSON, 2004). Esse instrumento foi adaptado culturalmente para a língua portuguesa por Barros e Alexandre (2003), apresentando uma confiabilidade variando de 0,88 a 1 segundo o coeficiente de Kappa e validado por Pinheiro, Tróccoli e Carvalho (2002), mostrando bom índice de validade concorrente para a versão brasileira.
0 questionário utilizado (autoaplicado) apresenta uma figura humana com vistas de costas relacionadas a cada área anatômica para a verificação da presença de queixas musculoesquelética nos últimos sete dias. Para cada região foi considerado um índice de queixas que variaram de um a cinco, sendo 1) sem queixas, 2) queixas leves, 3) queixas moderadas, 4) queixas consideráveis e 5) queixas intensas (CORLETT; BISHOP, 1976). Considerando-se a utilização do questionário como referencial teórico, optou-se por definir sintomas osteomusculares como o autorrelato de dor, desconforto, formigamento ou dormência (BARROS; ALEXANDRE, 2003).

Para a análise dos dados foi utilizada estatística descritiva por meio do percentual das respostas. Para as comparações dos percentuais daqueles que praticam e que não praticam as atividades foi utilizado o teste qui-quadrado, com nível de significância de 5\%.

\section{Resultados}

\subsection{A ginástica laboral desenvolvida}

As atividades desenvolvidas dentro da empresa são alongamentos ministradas por um profissional de educação física. A frequência de realização da ginástica laboral era duas vezes na semana, com duração de 15 minutos.

Para a realização dos exercícios não há horários definidos, sendo que cada colaborador realiza em um horário diferenciado, no final do expediente de trabalho. Os alongamentos são desenvolvidos de modo individual e/ou coletivo dependendo da disponibilidade dos trabalhadores e movimento de clientes na instituição.

Especificamente relacionando os tipos de alongamentos pode-se dizer que estes são priorizados para a cadeia posterior, principalmente para a região do pescoço e membros superiores. Assim, os resultados apresentados com relação às queixas musculoesqueléticas dos trabalhadores enfocam os membros superiores (ombros, braços, cotovelos, antebraço, punhos e mãos) e na região do tronco (cervical, região superior e do meio das costas e lombar).

\subsection{As queixas musculoesqueléticas dos trabalhadores}

De acordo com os relatos dos colaboradores não houve queixas consideradas como intensas para nenhuma região corporal. As queixas de maior intensidade (intensidade 4), nos membros superiores, 
foram relacionadas aos ombros, braço direito e mão direita. A Tabela 1 ilustra os resultados relacionados às comparações dos membros superiores entre os praticantes e não praticantes de ginástica laboral.

De acordo com esses resultados, pôde-se observar que não foram encontradas diferenças estatisticamente significativas relacionando a intensidade da dor nos diferentes grupos. Porém, quando a região do tronco foi analisada, esses resultados foram diferentes, no que tange à região da cervical. As queixas nesta região se mostraram de forma que os praticantes de ginástica laboral relacionam mais queixas leves enquanto que os que não praticam ginástica laboral relacionam queixas de maior intensidade, como as moderadas (intensidade 3) e consideráveis (intensidade 4). Para as outras regiões do tronco (superior, meio e lombar) não foram encontradas diferenças estatisticamente significativas com relação à intensidade em cada grupo. A Tabela 2 ilustra os resultados das queixas musculoesqueléticas na região do tronco dos praticantes e não praticantes de ginástica laboral.

\section{Discussão}

O objetivo deste estudo foi identificar a intensidade das queixas musculoesqueléticas de praticantes e não praticantes de ginástica laboral de colaboradores de uma instituição financeira. Conforme discute Oliveira (2007), a ginástica laboral visa prevenir e diminuir as doenças ocupacionais, o estresse e o absenteísmo; melhorar as condições de trabalho, a qualidade de vida e o relacionamento interpessoal; e aumentar a produtividade e qualidade dos serviços prestados.

Tabela 1. Resultados das comparações dos membros superiores entre os praticantes e não praticantes de ginástica laboral.

\begin{tabular}{|c|c|c|c|c|c|}
\hline & Sem queixas & Queixas leves & Queixas moderadas & Queixas consideráveis & p-valor* \\
\hline \multicolumn{6}{|c|}{ Região do ombro esquerdo } \\
\hline Praticantes & $11,11 \%(n=1)$ & $33,33 \%(n=3)$ & $44,44 \%(n=4)$ & $11,11 \%(n=1)$ & \multirow{2}{*}{0,694} \\
\hline Não praticantes & $0,00 \%(\mathrm{n}=0)$ & $28,57 \%(\mathrm{n}=2)$ & $42,86 \%(n=3)$ & $28,57 \%(\mathrm{n}=2)$ & \\
\hline \multicolumn{6}{|c|}{ Região do ombro direito } \\
\hline Praticantes & $11,11 \%(n=1)$ & $22,22 \%(n=2)$ & $44,44 \%(n=4)$ & $22,22 \%(n=2)$ & \multirow{2}{*}{0,824} \\
\hline Não praticantes & $0,00 \%(\mathrm{n}=0)$ & $28,57 \%(n=2)$ & $42,86 \%(n=3)$ & $28,57 \%(n=2)$ & \\
\hline \multicolumn{6}{|c|}{ Região do braço esquerdo } \\
\hline Praticantes & $55,56 \%(n=5)$ & $22,22 \%(n=2)$ & $22,22 \%(n=2)$ & $0,00 \%(n=0)$ & \multirow{2}{*}{0,209} \\
\hline Não praticantes & $14,29 \%(n=1)$ & $57,14 \%(n=4)$ & $28,57 \%(n=2)$ & $0,00 \%(n=0)$ & \\
\hline \multicolumn{6}{|c|}{ Região do braço direito } \\
\hline Praticantes & $33,33 \%(\mathrm{n}=3)$ & $44,44 \%(n=4)$ & $11,11 \%(n=1)$ & $11,11 \%(n=1)$ & \multirow{2}{*}{0,362} \\
\hline Não praticantes & $14,29 \%(n=1)$ & $85,71 \%(n=6)$ & $0,00 \%(n=0)$ & $0,00 \%(n=0)$ & \\
\hline \multicolumn{6}{|c|}{ Região do cotovelo esquerdo } \\
\hline Praticantes & $66,67 \%(n=6)$ & $33,33 \%(\mathrm{n}=3)$ & $0,00 \%(n=0)$ & $0,00 \%(n=0)$ & \multirow{2}{*}{0,504} \\
\hline Não praticantes & $57,14 \%(n=4)$ & $28,57 \%(n=2)$ & $14,29 \%(n=1)$ & $0,00 \%(n=0)$ & \\
\hline \multicolumn{6}{|c|}{ Região do cotovelo direito } \\
\hline Praticantes & $66,67 \%(n=6)$ & $11,11 \%(n=1)$ & $22,22 \%(n=2)$ & $0,00 \%(n=0)$ & \multirow{2}{*}{0,411} \\
\hline Não praticantes & $85,71 \%(n=6)$ & $14,29 \%(n=1)$ & $0,00 \%(n=0)$ & $0,00 \%(n=0)$ & \\
\hline \multicolumn{6}{|c|}{ Região do antebraço esquerdo } \\
\hline Praticantes & $66,67 \%(n=6)$ & $22,22 \%(n=2)$ & $11,11 \%(n=1)$ & $0,00 \%(n=0)$ & \multirow{2}{*}{0,915} \\
\hline Não praticantes & $71,43 \%(n=5)$ & $14,29 \%(n=1)$ & $14,29 \%(n=1)$ & $0,00 \%(n=0)$ & \\
\hline \multicolumn{6}{|c|}{ Região do antebraço direito } \\
\hline Praticantes & $55,56 \%(n=5)$ & $22,22 \%(n=2)$ & $22,22 \%(n=2)$ & $0,00 \%(n=0)$ & \multirow{2}{*}{0,411} \\
\hline Não praticantes & $71,43 \%(n=5)$ & $28,57 \%(\mathrm{n}=2)$ & $0,00 \%(n=0)$ & $0,00 \%(n=0)$ & \\
\hline \multicolumn{6}{|c|}{ Região do punho esquerdo } \\
\hline Praticantes & $66,67 \%(\mathrm{n}=6)$ & $33,33 \%(n=3)$ & $0,00 \%(n=0)$ & $0,00 \%(n=0)$ & \multirow{2}{*}{0,504} \\
\hline Não praticantes & $57,14 \%(n=4)$ & $28,57 \%(n=2)$ & $14,29 \%(n=1)$ & $0,00 \%(n=0)$ & \\
\hline \multicolumn{6}{|c|}{ Região do punho direito } \\
\hline Praticantes & $44,44 \%(n=4)$ & $33,33 \%(n=3)$ & $22,22 \%(n=2)$ & $0,00 \%(n=0)$ & \multirow{2}{*}{0,891} \\
\hline Não praticantes & $42,86 \%(n=3)$ & $42,86 \%(n=3)$ & $14,29 \%(n=1)$ & $0,00 \%(n=0)$ & \\
\hline \multicolumn{6}{|c|}{ Região da mão esquerda } \\
\hline Praticantes & $88,89 \%(n=8)$ & $11,11 \%(n=1)$ & $0,00 \%(n=0)$ & $0,00 \%(n=0)$ & \multirow{2}{*}{0,293} \\
\hline Não praticantes & $57,14 \%(n=4)$ & $28,57 \%(n=2)$ & $14,29 \%(n=1)$ & $0,00 \%(n=0)$ & \\
\hline \multicolumn{6}{|c|}{ Região da mão direita } \\
\hline Praticantes & $44,44 \%(n=4)$ & $33,33 \%(n=3)$ & $11,11 \%(n=1)$ & $11,11 \%(n=1)$ & \multirow{2}{*}{0,595} \\
\hline Não praticantes & $71,43 \%(n=5)$ & $14,29 \%(n=1)$ & $14,29 \%(n=1)$ & $0,00 \%(n=0)$ & \\
\hline
\end{tabular}

*Qui-quadrado. 
Tabela 2. Resultados das queixas musculoesqueléticas na região do tronco dos praticantes e não praticantes de ginástica laboral.

\begin{tabular}{|c|c|c|c|c|c|}
\hline & Sem queixas & Queixas leves & Queixas moderadas & Queixas consideráveis & p-valor* \\
\hline \multicolumn{6}{|l|}{ Região cervical } \\
\hline Praticantes & $11,11 \%(n=1)$ & $44,44 \%(n=4)$ & $0,00 \%(\mathrm{n}=0)$ & $44,44 \%(n=4)$ & \multirow{2}{*}{$0,049^{* *}$} \\
\hline Não praticantes & $0,00 \%(n=0)$ & $0,00 \%(n=0)$ & $42,86(n=3)$ & $57,14 \%(n=4)$ & \\
\hline \multicolumn{6}{|c|}{ Região superior das costas } \\
\hline Praticantes & $11,11 \%(n=1)$ & $22,22 \%(n=2)$ & $44,44(n=4)$ & $22,22 \%(n=2)$ & \multirow{2}{*}{0,777} \\
\hline Não praticantes & $0,00 \%(n=0)$ & $14,29 \%(n=1)$ & $57,14(n=4)$ & $28,57 \%(n=2)$ & \\
\hline \multicolumn{6}{|c|}{ Região do meio das costas } \\
\hline Praticantes & $22,22 \%(n=2)$ & $22,22 \%(n=2)$ & $44,44(n=4)$ & $11,11 \%(\mathrm{n}=1)$ & \multirow{2}{*}{0,824} \\
\hline Não praticantes & $14,29 \%(n=1)$ & $14,29 \%(n=1)$ & $42,86(n=3)$ & $28,57 \%(n=2)$ & \\
\hline \multicolumn{6}{|l|}{ Região lombar } \\
\hline Praticantes & $11,11 \%(n=1)$ & $0,00 \%(n=0)$ & $88,89 \%(n=8)$ & $0,00 \%(n=0)$ & \multirow{2}{*}{0,174} \\
\hline Não praticantes & $0,00 \%(n=0)$ & $28,57 \%(n=2)$ & $71,43 \%(n=5)$ & $0,00 \%(\mathrm{n}=0)$ & \\
\hline
\end{tabular}

Para Moreira, Cirelli e Santos (2005), as questões de trabalho que se associam a necessidade da ginástica laboral dentro das empresas são: aumento do ritmo de trabalho, alta velocidade de produção, movimentos repetitivos, estresse, etc. Além disso, a prática da ginástica laboral pode preparar o indivíduo fisiologicamente para a carga diária de trabalho.

Pode-se dizer que, no ambiente de trabalho, cabe às empresas investir em maiores esclarecimentos dos benefícios de um estilo de vida ativo. Para Ceschini, Romero e Lima (2007), a empresa pode atuar como um agente facilitador, promovendo programas de qualidade de vida no ambiente de trabalho para que os funcionários tenham a possibilidade, ao menos, de praticar um pouco mais de atividade física no dia a dia. Nesse sentido, a ginástica laboral vem sendo indicada e utilizada para as práticas no horário de trabalho. Realizada normalmente com sessões de 5 a 15 minutos, ela visa, sem atrapalhar as atividades do trabalho, proporcionar benefícios, que serão alcançados ao longo das práticas, por meio de exercícios específicos para cada atividade visando alongamento, fortalecimento muscular, coordenação motora e relaxamento (OLIVEIRA, 2007).

Mesmo que o trabalhador necessite parar as atividades do trabalho para realizar a ginástica laboral os estudos demonstram que há maior produtividade, menor custo com assistência médica, maior satisfação interna, melhor imagem externa e maiores lucros. Apesar da relevância demonstrada por autores como Paffenbarger e Hale (1975); Paffenbarger, Wing e Hyde (1978); Gauvin e Spence (1996); Martinez-Gonzalez et al. (1999); Troiano, Macera e Ballard-Barbash (2001) em se manter fisicamente ativo, segundo Salles-Costa et al. (2003) ainda há prevalência de inatividade física e os resultados encontrados pelo presente estudo corroboram com estas informações visto que 56,25\% dos colaboradores não participam das atividades proporcionadas pela empresa.
0 estudo de Ceschini, Romero e Lima (2007) que avaliou trabalhadores bancários da região de São Paulo mostrou uma média de $1,1 \pm 0,4$ dias na semana de práticas para atividades físicas vigorosas durante $11,1 \pm 1,7$ minutos. Para atividades moderadas, os valores médios foram $1,5 \pm 0,5$ dias na semana e 23,2 \pm 7,3 minutos por sessão. Os maiores valores médios foram observados para a caminhada com uma média de 2,7 $\pm 0,9$ dias na semana, com duração média de 29,8 $\pm 6,5$ minutos por sessão. Os autores indicam que somando todas as intensidades de atividades dos trabalhadores observa-se uma média semanal de 58,2 \pm 15,3 minutos, o que não contempla as recomendações de 150 minutos de práticas por semana.

Mesmo com índices elevados de inatividade física, segundo Martins e Duarte (2000) nenhuma atividade física ou exercício físico deve ser colocado como obrigatório para os trabalhadores, ou seja, essas práticas devem ser realizadas de livre e espontânea vontade. Segundo Logen (2003), a ginástica laboral pode ser encarada pelos trabalhadores como uma tarefa extra, podendo prejudicar a meta almejada. Portanto, é pertinente lembrar que a ginástica laboral deve ser apresentada aos trabalhadores como uma atividade optativa, sendo os exercícios realizados durante o horário de trabalho, sem comprometer as pausas existentes.

0 estudo de Maciel et al. (2005) indicou que muitas vezes o trabalhador é obrigado a assinar um "termo de compromisso" que, na prática, tem sido utilizado como um documento que isenta a empresa da responsabilidade pela ocorrência da doença ocupacional, caso ela venha a ocorrer. A inversão da relação de causa e efeito é grave, pois pode levar a um sentimento de inadequação do trabalhador. Além disso, não se pode incumbir ao trabalhador que o mesmo assuma a responsabilidade de seu condicionamento físico, 
assim como se faz com o desempenho e qualidade determinados pela gestão da empresa.

A responsabilidade pelas questões trabalhadas durante a ginástica laboral deve ser do profissional que prescreve o treinamento. Porém, o trabalho será completo e terá um bom andamento quando houver cooperação, interesse do trabalhador e incentivo da empresa. Para tanto é importante a explicação e o entendimento dos reais benefícios que a prática de algum tipo de exercício físico proporciona, não só para as questões relacionadas ao trabalho, mas também para as questões de saúde e qualidade de vida. Assim, é importante a atuação dos profissionais de educação física junto às instituições bem como da intervenção da ergonomia enquanto melhora das condições de trabalho e saúde. Martins (2000) salienta que a relevância da ergonomia num programa de ginástica laboral se dá em consideração ao trabalhador que passa a maior parte do seu tempo num ambiente que, se não for adequado e confortável, pode reprimir grande parte dos benefícios conquistados pela prática de exercício.

A ergonomia tem desempenhado um papel central na prevenção das afecções dos trabalhadores, pois permite a avaliação das condições e ambientes de trabalho, propostas e implementação de soluções técnicas (relacionadas a mudanças nos equipamentos e ambientes físicos) e administrativas (relacionadas à programação de pausas e rodízios e mudanças na organização e conteúdo das atividades), reduzindo assim a frequência das doenças, os custos financeiros com indenizações e o sofrimento dos trabalhadores (MAClEl et al., 2005).

Lacerda et al. (2005) indicam que os trabalhadores que desenvolvem lesões, especialmente aqueles com diagnóstico confirmado clinicamente, tendem a mudar seus papéis dentro da organização, o que significa alterar a função dos funcionários com o objetivo de torná-los menos expostos a movimentos repetitivos.

De forma geral, essas considerações são importantes em função das exigências de qualificação dos trabalhadores. Atualmente, essas exigências incidem tanto sobre aspectos técnicos da ocupação (por exemplo, conhecimentos de informática, contabilidade financeira, aplicações, avaliação de riscos, dentre outros) como sobre aspectos comportamentais, associados à polivalência. Segundo Segnini (1999), essa última exigência merece destaque, uma vez que se refere a comportamentos esperados do trabalhador que modulam determinadas formas de ser e de trabalhar: disposição e habilidade para vender produtos e serviços, para competir, ser amável, comunicativo, equilibrado, responder às demandas dos clientes, saber fidelizar o cliente para a instituição, ser capaz de adaptar-se ao intenso ritmo de trabalho e tolerar a pressão e o estresse (JACQUES; AMAZARRAY, 2006). 0 estudo de Oliveira e Campello (2006) relacionou dentro de agências problemas como: exigência de metas, volume de trabalho excessivo, inadequação numérica de pessoal, exigência de esforço mental, repetitividade das tarefas, prolongamento da jornada e pausas insuficientes.

Com essas características somadas aos problemas do uso do posto de trabalho há queixas de dor/desconforto no desenvolvimento das atividades. Brandão, Horta e Tomasi (2005) mostraram a prevalência de sintomas de distúrbios osteomoleculares em três ou mais regiões anatômicas em bancários, sendo que em função das queixas alguns trabalhadores chegaram a evitar o trabalho. Segundo Lima (2006), as queixas dos bancários estão expressas não só nas histórias, mas também nos documentos e nas ações do sindicato, que demonstram que as doenças estão relacionadas à organização do trabalho. 0 foco da organização do trabalho como interveniente para a existência de queixas musculoesqueléticas também foi citado pelo estudo de Lacerda et al. (2005).

Oliveira e Campello (2006) encontraram que os prejuízos à saúde em instituições privadas, como no caso do presente estudo, estão associados principalmente às questões de cargas posturais e de mobiliário. Lacerda et al. (2005) sugerem que as queixas apresentadas pelos trabalhadores são devido às condições ergonômicas nos locais de trabalho que exigem, por exemplo, hiperflexão dos pulsos durante a digitação e outras posturas. Essas questões indicam que estratégias de educação em saúde e segurança do trabalho são necessárias. Além disso, conhecer as possibilidades do próprio corpo torna o trabalho mais seguro e com menores possibilidades de acometimento. As necessidades de intervenções no trabalho com vistas para os quadros de saúde-doença são corroboradas pelas indicativas de Lacerda et al. (2005), que demonstraram que muitos bancários ainda continuam a desenvolver suas atividades mesmo quando lesionados.

Estudos como o de Martins e Martins (2000), Pinto e Souza (2004) e Santos et al. (2007) relatam os resultados positivos com as práticas no que tange às questões de diminuição da sintomatologia musculoesquelética, o que não reflete os resultados aqui encontrados. Por outro lado, Longen (2003) esclarece que a eficácia e a validade da ginástica laboral podem ser questionadas. Para o autor, os programas de ginástica laboral quando adotados de forma isolada como proposta preventiva de lesões por esforço repetitivo ou por distúrbios osteomusculares relacionados ao trabalho são extremamente limitados. Além disso, para Maciel et al. (2005), estudos que 
demonstrem resultados conclusivos para a prevenção dessas problemáticas ainda são necessários.

No presente estudo, a maior parte das análises não mostrou diferenciação entre os sintomas dos indivíduos que praticam a ginástica laboral proposta pela empresa e os que não praticam. Um ponto de importante consideração é relacionado à frequência semanal de práticas. Para Pieron (2004) a periodicidade deve ser de no mínimo três vezes na semana, o que remete à necessidade de aumento da frequência semanal para a realização das práticas físicas dos trabalhadores avaliados. Para Ceschini, Romero e Lima (2007), deve-se aumentar o nível de atividade física diária dos funcionários. Na verdade, a ginástica laboral, realizada dentro das empresas, tem indicações de ser executada durante três vezes por semana, ou diariamente, por períodos que variam de 8 a 12 minutos, durante a jornada de trabalho (MACIEL et al., 2005), o que de fato necessita de maior frequência semanal, visto que os trabalhadores investigados pelo presente estudo a realizam com frequência de duas vezes na semana.

Além disso, segundo Pate et al. (1995), para obter os diversos benefícios para a saúde, a recomendação universal da prática de atividade física em adultos é de, pelo menos, cinco dias na semana, 30 minutos por dia, de intensidade leve a moderada e de forma contínua (única sessão) ou acumulada (duas ou mais sessões por dia), além de poder ser praticada no tempo de lazer, em atividades em casa, como forma de transporte ou em atividades praticadas no ambiente de trabalho.

Conforme definições de Gravina e Rocha (2006), a ginástica laboral apresenta-se diferenciada tanto aos objetivos quando ao horário de aplicação. No caso do presente estudo, os trabalhadores desenvolvem a atividade no final do expediente, o que segundo Zilli (2002) é considerada como sendo de relaxamento e visa o alívio das tensões, a redução do estresse e dos índices de desavenças no trabalho e em casa, com consequente melhora da função social. No entanto, pode-se enfatizar que as atividades poderiam ter outra ênfase, como, por exemplo, no meio do expediente com o objetivo de melhorar a circulação com a retirada de resíduos metabólicos, modificar a postura no trabalho, reabastecer os depósitos de glicogênio e prevenir a fadiga muscular. Assim, para o mesmo autor, essa atividade seria considerada como compensatória e não mais como de relaxamento.

De qualquer forma, Maciel (2000) coloca que a prevenção é a melhor forma de cuidar ou eliminar as causas antes que aconteça. Nesse mesmo sentido, não foram investigados o nível de atividade física de cada colaborador nem as práticas realizadas no momento de lazer, o que pode limitar os resultados encontrados. Essas análises seriam importantes, pois, segundo Dejours (1992), a compensação natural das "violências" do trabalho acontece no tempo livre. Além disso, o conhecimento dos motivos para a realização das práticas e as expectativas dos trabalhadores também não foram investigados e são importantes para a elaboração das práticas físicas.

Considerando as queixas musculoesqueléticas, foram observadas queixas em todas as regiões corporais, porém parece que a prática de ginástica laboral foi eficiente apenas para as diferenças na região da cervical, o que vai ao encontro dos estudos que relatam os benefícios das práticas físicas. Para Silva (1999), Murofuse e Marziale (2001) e Brandão, Horta e Tomasi (2005), os indivíduos considerados sedentários são mais acometidos pelos sintomas musculoesqueléticos quando comparados àqueles considerados ativos.

Especificamente vinculando o trabalho no sistema financeiro, podem-se relacionar as posturas e movimentos repetitivos ao se associar as queixas encontradas. Segundo Maciel et al. (2005), as estatísticas oficiais do INSS (Instituto Nacional de Seguridade Social, MPAS, 2003) relacionam que em bancários a doença por esforço repetitivo é o principal motivo de afastamento do trabalho. Então, pode-se considerar a postura de trabalho como sendo um fator gerador de distúrbio osteomuscular, principalmente se associada ao uso de equipamentos inadequados, o que demonstra a necessidade de intervenções em ergonomia. No entanto, o estudo de Martins Junior e Saldanha (2009) indica que os casos de adoecimento dos trabalhadores das empresas bancárias são tratados por médicos particulares ou clínicas ligadas à empresa, não sendo fornecidas informações desses casos à Previdência Social, comprometendo as estatísticas de agravos à saúde do trabalhador no país.

No estudo de Brandão, Horta e Tomasi (2005), os bancários que passavam a maior parte da jornada sentados apresentaram quase $30 \%$ mais sintomas de distúrbios osteomusculares do que os demais, provavelmente por permanecerem numa mesma posição durante um longo período, além de utilizarem equipamentos de trabalho muitas vezes mal posicionados.

Silva (1999), ao avaliar 189 trabalhadores bancários, encontrou frequência de lombalgia em 108 trabalhadores. Além disso, segundo Brandão, Horta e Tomasi (2005), aqueles que utilizavam o terminal on-line nas suas tarefas referiram 98\% mais dor do que aqueles que não o utilizavam, e 42\% referiram mais dor ao utilizar a máquina autenticadora. As frequências das queixas foram principalmente na região do pescoço, seguido dos ombros, lombar, mãos, pés e joelhos (SILVA, 1999). 0 estudo de Lacerda et al. (2005) mostrou 56\% dos trabalhadores 
acometidos pelos sintomas dos membros superiores, sendo o gênero feminino e a ocupação, como caixa ou escriturário, fatores de risco musculoesqueléticos.

De fato, o trabalho realizado pelos trabalhadores de instituições financeiras se mostra com prejuizos no que tange à integridade física associada às queixas musculoesqueléticas. Assim como no estudo de Longen (2003), de forma geral o programa de atividade física mostrou-se insuficiente mediante as necessidades de intervenção, uma vez que apenas a região da cervical mostrou-se diferenciada

\section{Considerações finais}

De acordo com os resultados encontrados no presente estudo, pode-se dizer que as práticas em ginástica laboral, realizadas em seções de 15 minutos duas vezes na semana, não foram suficientes para diferenciar a intensidade das queixas musculoesqueléticas daqueles que praticam e não praticam a atividade.

A ginástica laboral mostrou resultados positivos apenas para a região da cervical $(p=0,049)$. As queixas nessa região se mostraram de forma que os praticantes de ginástica laboral relacionam mais queixas leves, enquanto os que não praticam ginástica laboral relacionam queixas de maior intensidade, como as moderadas (intensidade 3) e consideráveis (intensidade 4).

Sugerem-se novos estudos relacionando o nível de atividade física dos trabalhadores, considerando não apenas as práticas realizadas nos locais de trabalho, mas também nos momentos de lazer. Além disso, a avaliação dos indivíduos antes do início da proposta de ginástica laboral e um acompanhamento regular durante as práticas são importantes estratégias para o sucesso.

\section{Referências}

BARROS, E. N. C.; ALEXANDRE, N. M. C. Crosscultural adaptation of the Nordic musculoskeletal questionnaire. International Nursing Review, v. 50, n. 2, p. 101-108, 2003. PMid:12752909. http://dx.doi. $\operatorname{org} / 10.1046 / j .1466-7657.2003 .00188 . x$

BRANDÃO, A. G.; HORTA, B. L.; TOMASI, E. Sintomas de distúrbios osteomusculares em bancários de Pelotas e região: prevalência e fatores associados. Revista Brasileira de Epidemiologia, v. 8, n. 3, p. 295-305, 2005.

CESCHINI, F. L.; ROMERO, J.; LIMA, V. Prevalência de inatividade física e fatores associados em bancários. Revista Brasileira de Ciências da Saúde, v. 3, n. 12, p. 3-11, 2007.

CORLETT, E. N.; BISHOP, R. P. A technique for assessing postural discomfort. Ergonomics, v. 19, p. 175-182, 1976. PMid:1278144. http://dx.doi. org/10.1080/00140137608931530
DEJOURS, C. A loucura do trabalho. 5. ed. São Paulo: Cortez, 1992.

ELY, H. B. Mudanças tecnológicas nos bancos brasileiros. São Paulo: SEE/SEBE, 1996.

ENGQUIST, K.; ORBAEK, P.; JAKOBSSON, K. Musculoskeletal pain and impact on performance in orchestra musicians and actors. Medical Problems of Performing Artists, v. 19 , n. 2 , p. 55-61, 2004

GAUVIN, L.; SPENCE, J. C. Physical activity and psychological well-being: Knowledge base, currents issues and caveats. Nutrition Reviews, v. 54, p. 53-65, 1996. http://dx.doi. org/10.1111/j.1753-4887.1996.tb03899.x

GRAVINA, M. E. R.; ROCHA, L. E. Lesões por Esforços Repetitivos em bancários: reflexões sobre o retorno ao trabalho. Cadernos de Psicologia Social do Trabalho, v. 9, n. 2, p. 41-55, 2006

JACQUES, M. G. C.; AMAZARRAY, M. R. Trabalho bancário e saúde mental no paradigma da excelência. Boletim da Saúde, v. 20, n. 1, p. 93-106, 2006.

KUORINKA, 1. et al. Standardized Nordic Questionnaires for the Analysis of Musculoskeletal Symptoms. Applied Ergonomics, v. 18, n. 3, p. 233-37, 1987. http://dx.doi. org/10.1016/0003-6870(87)90010-X

LACERDA, E. M. et al. Prevalence and associations of symptoms of upper extremities, repetitive strain injuries (RSI) and 'RSl-like condition'. A cross sectional study of bank workers in Northeast Brazil. Public Health, v. 5, n. 107, p. 1-10, 2005. PMid:15627405. PMCid:548283.

LIMA, M. E. A. Os problemas de saúde na categoria bancária: consideracões acerca do estabelecimento do nexo causal. Boletim da Saúde, v. 20, n. 1, p. 57-68, 2006.

LONGEN, W. C. Ginástica laboral na prevenção de LER/DORT: Um estudo reflexivo em uma linha de produção. 2003. 130 F. Dissertação (Mestrado em Engenharia da Produção)-Universidade Federal de Santa Catarina, Florianópolis, 2003.

MACIEL, R. H. Prevenção da LER/DORT: o que a ergonomia pode oferecer. Cadernos de Saúde do Trabalhador, 2000. 26 p.

MACIEL, R. H. et al. Quem se Beneficia dos Programas de Ginástica Laboral? Cadernos de Psicologia Social do Trabalho, v. 8, p. 71-86, 2005.

MARTINEZ-GONZALEZ, M. A. et al. Physical inactivity, sedentary lifestyle and obesity in the European Union. International Journal of Obesity Related Metabolism Disorders, v. 23, p. 1192-1201, 1999. http://dx.doi. org/10.1038/sj.ijo.0801049

MARTINS, C. 0. Universidade Federal de Santa Catarina. Efeitos da ginástica laboral em servidores da reitoria da UFSC. 2000. 109 F. Dissertação (Mestrado em Engenharia da Produção)-Universidade Federal de Santa Catarina, Florianópolis, 2000.

MARTINS, C. 0.; DUARTE, M. F. S. Efeitos da ginástica laboral em servidores da Reitoria da UFSC. Revista Brasileira de Ciência e Movimento, v. 8, n. 4, p. 7-13, 2000.

MARTINS, C. 0.; MARTINS, M. 0. Eficácia da ginástica laboral na prevenção aos DORT e sua aceitação por funcionários públicos de Florianópolis-SC. In: SIMPÓSIO INTERNACIONAL DE CIÊNCIAS DO ESPORTE - ATIVIDADE FÍSICA, 23., 2000, São Paulo. Anais... São Paulo, 2000. p. 173. 
MARTINS JÚNIOR, M.; SALDANHA, M. C. W. Doenças sem doentes: ocorrência de distúrbios osteomusculares relacionados ao trabalho - DORT nos operadores de caixa de um banco. Ação Ergonômica, v. 4, n. 1, p. 26-38, 2009.

MOREIRA, P. H. C.; CIRELLI, G.; SANTOS, P. R. B. A importância da Ginástica Laboral na diminuição das algias e melhora da qualidade de vida do trabalhador. Fisioterapia Brasil, v. 6, n. 5, p. 349-353, 2005.

MUROFUSE, N.; MARZIALE, M. Mudanças no trabalho e na vida de bancários portadores de L.E.R. Revista Latino-Americana de Enfermagem, v. 9, n. 4, p. 19-25, 2001.

OLIVEIRA, J. R. G. 0. A prática da Ginástica Laboral. 3. ed. Rio de Janeiro: Sprint; 2006.

OLIVEIRA, J. R. G. A importância da ginástica laboral na prevenção de doenças ocupacionais. Revista de Educação Física, n. 139, p. 40-49, 2007.

OLIVEIRA, P. A. B.; CAMPELlO, J. C. Cargas de trabalho e seu impacto sobre a saúde: estudo de caso em quatro instituições financeiras em porto alegre. Boletim da Saúde, v. 20, n. 1, p. 69-92, 2006

PAFFENBARGER JUNIOR, R. S.; HALE, W. E. Work activity and coronary heart disease. New England Journal of Medicine, v. 292, p. 545-550, 1975. PMid:1128551. http://dx.doi.org/10.1056/NEJM197503132921101

PAFFENBARGER, R. S.; WING, A. L.; HYDE, R. T. Physical activity as an index of heart attack risk in college alumni. American Journal of Epidemiology, v. 108, p.161-175, 1978.

PATE, R. R. et al. Physical activity and public health: a recommendation from the Centers for Disease Control and Prevention and the American College of Sports Medicine. Jama, v. 273, p. 402-407, 1995. http://dx.doi. org/10.1001/jama.1995.03520290054029
PIERON, M. Estilo de vida, práticas de atividades físicas e esportivas, qualidade de vida. Fitness \& Performance Journal, v. 3, n. 1, p. 10-18, 2004.

PINHEIRO, F. A.; TRÓCCOLI, B. T.; CARVALHO, C. V. Validação do Questionário Nórdico de Sintomas Osteomusculares como medida de morbidade. Revista de Saúde Pública, v. 36, n. 3, p. 307-12, 2002. http://dx.doi.org/10.1590/ S0034-89102002000300008

PINTO, A. C. C. S.; SOUZA, R. C. P. A Ginástica laboral como ferramenta para a melhoria da qualidade de vida no setor de cozinha em restaurantes. 2004. Ensaios de Ergonomia. Disponivel em: <http://www.eps.ufsc.br/ergon/revista/ artigos/rita.PDF>. Acesso em: 22 set. 2009.

SALLES-COSTA, R. et al. Gênero e prática de atividade física de lazer. Cadernos de Saúde Pública, v. 19, p. 325-333, 2003. Suplemento 2.

SANTOS, A. F. et al. Benefícios da ginástica laboral na prevenção dos distúrbios osteomusculares relacionados ao trabalho. Arquivos de Ciências da Saúde da Unipar, v. 11, n. 2, p. 99-113, 2007.

SEGNINI, L. R. P. Reestruturação nos bancos no Brasil: desemprego, subcontratação e intensificação do trabalho. Educação e Sociedade, v. 20, n. 67, p. 183-209, 1999. http://dx.doi.org/10.1590/S0101-73301999000200007

SILVA, A. R. L. Correlação entre lombalgia e as características antropométricas de trabalhadores bancários da cidade de Londrina - PR. 1999. 121 f. Tese (Doutorado em Engenharia de Produção)-Universidade Federal de Santa Catarina, Florianópolis, 1999.

TROIANO, R. P.; MACERA, C. A.; BALLARD-BARBASH, R. Be physically active each day. Howcan we know? Journal of Nutrition, v. 131, p. 451-460, 2001.

ZILLl, C. M. Manual de cinesioterapia/Ginástica Laboral: Uma Tarefa Interdisciplinar com Ação Multiprofissional. Curitiba: Lovise, 2002. 102 p.

\title{
Musculoskeletal complaints and labor gymnastic practice of financial institution employees
}

\begin{abstract}
This research identified the musculoskeletal complaints of 16 financial institution workers, inserted and not inserted in labor gymnastic activities, through mean body map questionnaires. The Chi-Square test was applied to data analysis with 5\% significance level. The labor gymnastic group showed positive results only for the cervical region analysis $(p=0.049)$. In the cervical region, the labor gymnastic group showed less intense complaints $(44.44 \% ; n=4)$, in contrast to the non-gymnastic group. These workers, in turn, more intensely complained as moderate (intensity 3) $(42.86 \% ; n=3)$ and considerable (intensity 4) $(57.14 \% ; n=4)$. Labor gymnastic practices, performed twice a week, did not bring significant differences in musculoskeletal complaints in the analyses of most body regions. These results indicate the need for adjustments in the activities so that greater effectiveness in the musculoskeletal situation can be achieved.
\end{abstract}

Keywords

Musculoskeletal complaints. Bank clerks labor gymnastic. Ergonomics. 